\title{
La miseria de la historia cientificista: Reflexiones sobre actitudes y prácticas del conocimiento histórico
}

\author{
Roch Little \\ Universidad Nacional de Colombia
}

\begin{abstract}
Resumen
Mediante aforismos el autor debate acerca de la "miseria de la ciencia" en el conocimiento histórico. Con esta expresión argumenta la superficialidad de todas las pretensiones de la reflexión epistemológica, como base de la "historia científica". Esta forma de reflexión ignora deliberadamente un elemento importante: a los historiadores como productores de este conocimiento.
\end{abstract}

\begin{abstract}
Using the form of aphorism, the author wants to debate about the "misery of science" in Historical knowledge. With this term, he wants to argüe about the superficiality of all pretensions of epistemological reflexion as a base for a "scientific history". The reason is that this kind of reflexion ignores deliberately an important element: the historian as a living producer of this knowledge.
\end{abstract}

Para N.

\section{Prólogo}

La reflexión que presento parte de una crisis. Una crisis frente a un campo del conocimiento, la historia, cuya legitimidad ha sido afectada desde hace más de doscientos años por un principio que debía, según se pretendía, fortalecerlo. Hablo de la historia practicada desde el paradigma cientificista, un paradigma que hoy en 
día, está fuertemente cuestionado. ¿Sería que nos equivocamos de camino? Los que no se volvieron completamente insensibles, los que no se dejaron encantar por el canto de la sirena, o sobre todo, los que no se dejaron contaminar, están de repente dispuestos a reconocer su mea culpa. Hacerlo sí. Disculpándose de haberse equivocado. Advirtiendo sin embargo que esa equivocación fue cometida de buena fe, con las mejores intenciones del mundo.

¿Pero no sería oportuno preguntarse si estas buenas intenciones no constituyen, precisamente, la fuente de todo los daños causados? ¿Que la actitud cientificista frente al conocimiento histórico disimula malas intenciones? Vale la pena interrogarse sobre lo que más perjudica: ¿la mentira que sirve de vehículo a una intención no confesada, o la transmisión de verdades que tienen la mentira por fundamento?

Esta pregunta no aguanta más dilación. Suscita el cuestionamiento sobre los fundamentos de la ciencia histórica. Lo que se encuentra en la cabeza de los historiadores que se califican como "científicos"; cavar, analizar la composición de la tierra sobre la cual ésta reposa, más que interesarse en su constitución "epistemológica". Esto último es lo que no se ha hecho hasta ahora. La razón es obvia: hay riesgo de descubrir que lo que llamamos ciencia histórica se edificó sobre una base que no tiene nada que ver con lo científico, desde una estricta definición epistemológica. De hecho, aunque se puede afirmar con certeza que este edificio se construyó directamente sobre un suelo, no obstante, se trata de un suelo fangoso, hecho de mitos, de aspiraciones y de ambiciones de toda índole. En términos concretos, equivale decir que la historia es científica sólo por la actitud cientificista profesada de parte de los historiadores. En otras palabras, lo científico, en el conocimiento histórico, se asemeja a una práctica, a un ritual.

De ahí se descubre que tanto la elaboración como la defensa de la historia científica no es otra cosa que la elaboración y la defensa de una creencia en lo científico de la historia. Es decir que todo lo que se nos presenta actualmente como ciencia histórica se apoya sobre un vacío epistemológico.

Quedan entonces estas preguntas angustiosas, a las cuales este artículo no aportará ninguna respuesta definitiva. Al contrario, no constituyen más que el principio de una reflexión: ¿Existen bases sobre las cuales podría edificarse una auténtica historia 
científica? ¿Es todavía factible el proyecto cognoscitivo de una historia científica? Preguntas, como se puede constatar, difíciles de responder. Una cosa parece cierta sin embargo: si la historia científica es posible, el primer paso hacia su realización está todavía por hacer...

\section{I}

Las diferentes tendencias, ideologías o escuelas dentro de las cuales se identifican los historiadores, casi siempre han estado subordinadas a un tipo de "reflejo metafísico". El cual forma parte del comportamiento cultural fuertemente arraigado en sus respectivas idiosincrasias nacionales: empírico para los ingleses, idealista para los alemanes, formalista para los polacos, místico para los rusos, "airdu temps" para los franceses, y católico para los colombianos. Este reflejo repercute también en la concepción del ideal científico del conocimiento histórico.

\section{II}

Al contrario de lo que se cree, la famosa expresión de Ranke no ha sido refutada por el desarrollo de un pensamiento auténticamente científico (estructural); a la inversa, este constituye su prolongación natural. Pues si se burla de su pretensión de describir el pasado tal cual como ocurrió, la historia científica tal como se la concibe hoy en día, no es la impugnación, sino la heredera directa de Ranke, dado que persigue la misma sempiterna ambición en el plano interpretativo. ¿Qué es lo que quiere la historia como ciencia sino hacer del sentido del pasado un objeto? ¿Qué es lo que quiere sino llegar a comprender el pasado como cosa en sí? Aquí tenemos a un personaje cuya visión de la historia ha sido ridiculizada, con el fin de recuperarla después como propia, desembarazándola de su "idealismo", por supuesto. Es el viejo problema de siempre. Botamos a alguien por la puerta y se nos está devolviendo por la ventana...

\section{III}

Desde el punto de vista de la filosofía crítica (en el sentido entendido por Nietzsche) ${ }^{1}$, se descubre que la historia científica disimula en su relación con el

${ }^{1}$ Gilles Deleuze, Nietzsche y la Filosofía (Barcelona: Edición Anagrama, 1998), 105-56. 
pasado, un culto a la muerte. Es decir que el historiador inmoviliza el pasado para estudiarlo científicamente, a la manera de una experiencia de laboratorio (aunque siempre se ha defendido de proceder así, invocando una imposibilidad). Sin embargo, este olvida o quiere olvidar que de esta manera está asesinando el pasado. Gesto irreparable desde el punto de vista hermenéutico; pero inevitable dentro de esta lógica. Eso se da a partir del momento en que el historiador no solo quiere describir el pasado, sino también explicarlo (con el fin de revelar un objeto "en sí") y, sobre todo, buscar su sentido profundo (el objeto "en sí y para sí"). ¡Qué paradoja! Inmoviliza el movimiento presente - pasado (dentro del cual se puede percibir la "historicidad" según Dilthey²) para resaltar la dinámica del pasado. ¡Asesina en nombre de la vida!

\section{IV}

Entonces: ¡ningún diálogo con el pasado, ninguna búsqueda de una imagen objetiva u otras afirmaciones de la misma índole profesadas por el historiador cientificista! De hecho, este diálogo disimula un monólogo, donde el historiador interroga sus fuentes a la manera del policía que durante una indagatoria "intensa", muestra pruebas que acusan al sindicado, al mismo tiempo que le ordena callarse (dándole de vez en cuando una buena bofetada) cuando éste quiere explicarse.

\section{$\mathbf{V}$}

El pasado se revela ante nosotros a través de un lenguaje cuyo sentido ontológico (si es que existe uno) nos será perpetuamente cerrado. En consecuencia, todas las pretensiones epistemológicas profesadas por la historia científica no son otra cosa que vanas pretensiones. $\mathrm{O}$ peor, un peligroso reduccionismo. El pasado es una fuerza que se ejerce sobre nuestra razón a través de nuestros instintos. Su potencia se hace sentir por la sensación de angustia que tenemos frente al tiempo que pasa. Desde luego, lo que quiere el historiador, no es nada más que ampararse de este pasado, con el fin de controlarlo, con el fin de averiguar lo que está dispuesto a ver, lo que desea ver.

\footnotetext{
${ }^{2}$ Wilhem Dilthey, El Mundo Histórico (México: Fondo de Cultura Económica, 1944), 302-18.
} 
El tema de la investigación histórica. ¿Qué es lo que lo motiva? ¿Por qué trabajar sobre el campesinado francés del Antiguo Régimen o la mujer alemana durante la República de Weimar? ¿Por qué se trata de temas inéditos? ¿Por qué surge la necesidad de llenar un vacío temático sin el cual no puede haber comprensión total del período? Pregunto: ¿Qué es lo que nos motiva a escoger un tema en particular más que otro? ¿Serían los acontecimientos pasados in situl ¿ O más bien el impacto que ellos producen sobre nosotros? ${ }^{3}$ ¿Muéstrenme dónde está el santo virtuoso que, al principio, se lanzó en el estudio de un Napoleón, de un Washington o de un Bolívar porque eran "fríos" hechos históricos para analizar científicamente? ¿No sería que primero nos impresionaron sus actos? Y lo que es válido para los "héroes", ¿̇no es acaso lo mismo para cualquier acontecimiento? Desde luego, ¿todo conocimiento histórico no partiría de una relación emotiva frente a los hechos?

\section{VII}

De una gran sabiduría fue lo que oí un día por parte de un colega mío quien exclamó, a propósito de los fondos de archivos, que no eran otra cosa que un arrume de papeles amarillos y empolvados. Entendió que en sí el documento tiene un valor histórico sólo a partir del momento en que entra en interacción con los intereses cognoscitivos de un sujeto que conoce. En el caso contrario se trata sólo de una antigüedad, lo que es el problema de los anticuarios, de los estetas o de los museólogos.

\section{VIII}

Si Ranke no hubiese sido tan hipócrita en su deseo de ser científico, habría escrito: "el pasado tal como quiero que haya tenido lugar". Tenemos aquí a un artista de talento que se intoxicó con el más violento de los venenos que el intelecto humano, en su ilimitada perversidad, haya producido: el determinismo mecanicista.

${ }_{3}^{3}$ Friedrich Nietzsche, Aurore: Réflexions sur les Préjugés Moraux (París : Librairie Genérale Francaise, 1995), 231. 
Por querer ser "objetivo", Ranke ha negado su propio genio. Quiso describir y explicar a partir de una causalidad, por no tener que interpretar... Reproducir en lugar de crear. ¿El trabajo alienado, en el campo de la producción de conocimiento académico, sería más hondo que en el obrero? Vale la pena preguntárselo. Acaso:

¿Marx se habría equivocado de objetivo?

\section{IX}

Todo historiador que sueña en que el conocimiento histórico que produce sea la quintaesencia de lo científico (particularmente el que está obsesionado por las cuestiones técnicas) aspira de manera más o menos conscientemente a lo que pretendía Fustel de Coulanges. Afirmaba en efecto, que no hablaba de historia sino que la historia hablaba a través de él. Para lograr eso, no hay necesidad de manejar técnicas sofisticadas; un juego de Ouija es suficiente. Será tan ridículo como antes, pero por lo menos, tendrá el mérito de provocar la risa. Lo que no espoca cosa...

\section{$\mathbf{X}$}

Para los historiadores con pretensión cientificista, el pasado representa una empresa de escrutinio de artefactos de una época muerta, rigurosamente establecidos, y presentados en la forma de un relato mediante una intriga. ¡Buscad el error! ¿Pero acaso hay error?

\section{XII}

Veyne lo comprendió perfectamente: la historia tiene como meta primera la diversión. Luego el divertimento no excluye ni el aprendizaje, ni tampoco las implicaciones transcendentales en el plano cognoscitivo. ¡Al contrario! Con el divertimento se halla la forma más poderosa de conocimiento. A las personas que más hay que temer son a las que aprenden de la vida divirtiéndose. ¡Tened cuidado de los pedagogos que hacen reír a sus alumnos! Son los que, al final, más habrán aprendido. 


\begin{abstract}
XII
Eco lo demostró magistralmente en el Péndulo de Foucault. Cuándo se quiere ver sentido a toda costa, ¡se lo encuentra! Resultado: deslizamientos de alto calibre, pero sentido a pesar de todo... Porque, a fin de cuentas, más valen alucinaciones que no afirmar nada... Después de todo, es parte de la naturaleza humana querer la nada... ${ }^{4}$ Considerando, - pero los más cínicos, sabiéndolo conscientemente - que estos postulados no tienen ningún sentido, i sin embargo, nos hacen esperar la verdad que se podrá descubrir algún día! Desde luego, mirando el problema detenidamente, se puede afirmar que estos historiadores son bastante semejantes a los ministros británicos que siempre deben responder a las preguntas de la oposición. Cuando no se sabe exactamente, se evade; cuando no se sabe, se dilata; cuando no se sabe nada, se cambia el tema.
\end{abstract}

\title{
XIII
}

Por consiguiente, es interesante anotar hasta qué nivel de inconsecuencia los historiadores se dicen o pretenden ser científicos. Este problema constituye en sí un amplio tema de estudio que ocupará a los investigadores historiográficos de las próximas generaciones. De hecho, si hay que hablar de epistemología, este es el tema que hay que discutir de inmediato: la posibilidad de la historia como ciencia. Porque en el conocimiento histórico este término, que ha sido utilizado de mil y una maneras, constituye ahora una cáscara vacía. Es una palabra bella, que pretende dar a toda reflexión histórica un carácter "teórico". Popper hace tiempo denunció esta situación, con las críticas encarnizadas producidas en su tiempo (particularmente desde los marxistas). En mi opinión, la evidencia de Popper no fue lo suficientemente lejos: para comprobarlo, están los estudios racionalistas que diariamente evidencian el carácter "supersticioso" del sentimiento religioso; sin embargo, dichos estudios no han contribuido a disminuirlo (al contrario, tienden en este fin de milenio, a crecer aún más). Desde luego, la pregunta que hay que hacerse no consiste en saber si la historia puede o no ser una ciencia, y en el caso que lo sea, en qué condiciones (o lo que sería el colmo de la angustia

\footnotetext{
${ }^{4}$ Friedrich Nietzsche, Genealogía de la Moral (Madrid: Alianza, 1994), 186.
} 
cientificista: una ciencia "en construcción"), sino preguntarse ¿qué es lo que la historia, indudablemente una rama del conocimiento, ha logrado ser desde que se postula como una ciencia! Dicho en otras palabras: ¿qué es lo que se disimula tras la historia científica?

\section{XIV}

Desde luego: ¿cuáles son las implicaciones profundas detrás de la pretensión cientificista de la historia? Al principio, la idea de un pasado fijo, inamovible, muerto de alguna manera. Y es a partir de esta noción básica que todo el edificio de la historia científica se sostiene. En efecto, desde que está planteada la posibilidad de un pasado como objeto, es posible hablar de ciencia histórica (y no solamente de sus "técnicas", pues por este lado, nada diferenciaría a priori la historia del arte). Este concepto se expresa en la afirmación que concibe como objetos reales (huellas) del pasado los hechos establecidos desde las fuentes ${ }^{5}$. Este pasado-objeto es, para el historiador científico, un postulado axiomático, una adquisición indiscutible, un fundamento ontológico sobre el cual se ha edificado (ipor fin!) la legitimidad definitiva del conocimiento histórico. Luego esta posición implica que el pasado no solamente es una cosa en sí: es también un objeto puro, cognoscible en su totalidad o por lo menos en vía de serlo (este último representa una variante posible a partir del momento en que se trata de un objeto). Para lograr esta dimensión global y total del objeto histórico, hay que encontrar el sistema, la estructura o el método que hace surgir este objeto.

\section{XV}

Entonces, lo que quieren los historiadores científicos, lo que persiguen como meta última (sobre todo cuando incursionan en la pedagogía), es "domesticar" a los apasionados de la historia, haciéndolos "sufrir" a un punto tal (y ahí se encuentra la intención disimulada, "perversa", del método, entendido aquí en su sentido positivista) que llegarán progresivamente a reprimir, a rechazar con

\footnotetext{
5 Jerzy Topolski, "La Verdad Posmoderna en la Historiografía," en Pensar el Pasado, ed. Carlos Miguel Ortiz Sarmiento y Bernardo Tovar Zambrano (Santafé de Bogotá: Archivo General de la Nación, Universidad Nacional de Colombia, 1997), 184-85.
} 
repugnancia, a ver con desprecio todo lo que muestra cualquier tipo de relación con un conocimiento donde la imaginación está en juego. Cerrando así las puertas a los "creativos", la historia científica logró sin embargo crear una nueva situación paradójica: dejó de lado a todos los que habían legitimado el conocimiento histórico, confió todo su interés a los "mediocres" que, ellos sí, lo ilegitimaron.

\section{XVI}

Conclusión: lo científico, en la historia, plantea al principio, la perseverancia en el trabajo como respaldo para lograr la objetividad.

\section{XVII}

La actitud cientificista en el conocimiento histórico consiste en plasmar leyes objetivas y/o fundamentos estructurales en místicas de salvación.

\section{XVIII}

El pasado es una fuerza viva. Es la razón por la cual éste nos impacta tanto. De otra manera, ¿cómo podríamos interesarnos en él? Esta fuerza que, irresistiblemente, nos atrae y nos asusta al mismo tiempo (atracción típicamente 'occidental", eso porque muchas otras civilizaciones no padecen, como la nuestra, esta obsesión frente al tiempo que pasa), no puede conocerse ni directamen-te ni por el camino empírico y tampoco por el dialógico. Entonces, al historiador no le queda otra alternativa que ejercer su fuerza sobre el pasado, la cual proviene de su

curiosidad cognoscitiva. De esta manera, la relación con el pasado no puede resultar en otra cosa que en una relación de fuerza, una manifestación de poder cuyos términos establece el propio historiador. Así las respuestas que busca siempre se constituyen en su beneficio propio. Efectivamente, por más refinado que sea el método, por muy ético que se pretenda, siempre se disimula un juego de poder: el del historiador que busca en el pasado respuestas que satisfacen sus propias preguntas. En una palabra, éste ve en el pasado lo que quiere ver, y ahí se encuentra el secreto de lo exhaustivo: un apetito insaciable de ver. Aunque no 
quiera admitirlo, lo que busca en el pasado es una forma de legitimar el presente. Es la razón por la cual siempre se ataca encarnizadamente a los que como Croce o Collingwood, asumen conscientemente una posición presentista frente al conocimiento histórico. O más bien, consecuencia de dos milenios de influencia judeocristiana y de sus avatares secularizados, de la misión que el historiador cree estar llamado a cumplir en esta tierra poblada de "sufrimiento".

\section{XIX}

Cumplir con una misión. Comprometer sus estudios con la sociedad. Ahí se esconde la bestia que permite decir, desde hace tantas generaciones, torpezas en nombre de una historia científica. Son incompetencias que justamente, conforman todo el fundamento de la noción de ciencia en historia. La mentira de buscar con mayúscula, lo que se encontraría más allá de la vida individual, a nivel de la especie.

\section{XX}

¿Qué significa la historia al nivel de la especie? ¿Qué significa esta necedad kantiana? La búsqueda de las primeras estructuras sociológicas, económicas, psicológicas. ¿Y para qué? Para el servicio del Hombre, esta noción informe, vana, tan vana que no hay nada que esperar de ella, sino constataciones pesimistas, o en el peor de los casos, nihilistas. Vanitas vanitatum et omnias vanitas. ¡Vanidad! ¡Los antiguos griegos tenían frente al conocimiento, y sin tener todos los esquemas que tenemos hoy en día, cien veces más sabiduría que nosotros mismos! ¡Hay que sorprenderse, ellos que no esperaban nada, ni siquiera de sus dioses! Porque tendremos que admitirlo algún día: desde la óptica científica, la historia no tiene ninguna utilidad. Mucho menos si la hacemos con una finalidad filosófica: no sirve sino de soporte metafísico a la mentira. El camino a seguir para una nueva historia filosó-

fica está todavía por trazar. Es una historia que buscará las implicaciones genealógicas y arqueológicas del discurso científico dentro del conocimiento histórico (y de todas las creencias y convicciones que extraemos de ella de manera general). Antes de entender el pasado, tendrá que comprender lo que pasa en la cabeza de los historiadores. 


\section{XXI}

De aquí la importancia actual, la obsesión contemporánea de todas las reflexiones "epistemológicas", que se multiplicaron a la velocidad de los panecitos del evangelio, a tal ritmo que todo historiador digno de este nombre hoy en día - ¿y porque "parece bien" ? - se dedica en la presentación de sus propuestas a éstas reflexiones. El fenómeno es sintomático: reaccionan a los ataques dirigidos contra el conocimiento histórico, tanto por parte de los pensadores que reclaman el "giro lingüístico", como por parte de los posmodernos. Estos estudios epistemológicos revelan malestares profundos, los cuales también ilustran hasta qué punto el remedio que unos quisieron aplicar a la historia intoxicada de "narratividad" resultó más perjudicial que la "enfermedad". ¿Aquí se encuentra la explicación de tanta epistemología? ¿Calmar los sufrimientos de una enfermedad que no existe para buscar mientras tanto el remedio? En ciertos casos, los extremos por supuesto - aunque, si miramos el problema a fondo, ¿̇e trata realmente de casos extremos, entendidos como casos de excepción? - , no hay necesidad de drogas. Un solo placebo es suficiente ${ }^{6}$.

\section{XXII}

El historiador que se ha esforzado hasta ahora para que su disciplina parezca una ciencia o que, por lo menos, logró dar a sus trabajos un toque parecido, no hizo nada más que comportarse, en relación con el mundo de los conocimientos verdaderos, como un puro y auténtico "levantado". Más valdría que se comportara como lo hacía en tiempos pasados; en aquella época era o un aprendiz de filósofo o un escritor fracasado. De una manera u otra perjudicaba menos a su disciplina y a la sociedad que ahora...

\section{XXIII}

La mediocridad, las aproximaciones, las reducciones simplificadoras... ¡Nada de eso tiene que ver con la historia que desde hace rato es una disciplina científica! ¡Allí llegan todas las reacciones de indignación cuando provocadores del estilo de

${ }^{6}$ Nietzsche, Aforismos 54 y 94 en Aurora. 
Popper nos arrojan las aguas negras de nuestras pretensiones cientificistas en la cara! Ser una ciencia, yo primero quisiera que la historia lo fuera. Pero lo que Popper demostró con agudeza es cómo los conceptos que manejamos dentro del conocimiento histórico representan un nivel óptimo de racionalidad que establece los marcos de la comprensión científica para un problema dado. Por ejemplo la noción de ley, en el pensamiento científico, posibilitó las predicciones. Así Popper denuncia la falacia del historicismo, tendencia "enfermiza" del conocimiento histórico. La pretensión del historicismo es formular predicciones, las cuales a menudo, se revelan vagas en sus consecuencias futuras. Un ejemplo perfecto es la filosofía marxista de la historia, la cual presenta la dinámica del cambio de un modo de producción al otro, como resultado de un proceso histórico nomotético. Eso permite a Marx predecir que al capitalismo, actual modo de producción, le sucederá el socialismo, luego el comunismo. ¿Cuándo tendrá lugar eso? ¿En qué condiciones? ¿Dónde primero? Ningún marxista pudo predecir antes de octubre de 1917 que el primer estado gobernado por principios marxistas sería Rusia. ¡Empezando por el propio Marx! Incluso Lenin confesará cínicamente, a propósito de estos acontecimientos: "el poder estaba en la calle, [los bolcheviques] fuimos los primeros en recogerlo". La objeción de Popper se fundamenta sobre el principio que si una ley científica logra formular predicciones con gran nivel de exactitud, (como en el caso de la astronomía por ejemplo), (uno) el científico no puede referirse a esta noción sino con la misma ambición y el mismo grado de cercanía. Sin embargo, no es precisamente el caso de la historia, cuyos historiadores son los primeros en afirmar que el uso de este concepto no alcanza ni siquiera los niveles cognoscitivos mínimos logrados por las ciencias puras. De aquí proviene la respuesta de Popper, una respuesta brutal — verdad que hiere porque impacta por su simplicidad y su buen sentido, a la manera de Aristóteles - , que los historiadores no pueden referirse a un concepto como el de ley para explicar las regularidades históricas. Y ello por su carácter imperfecto. En otras palabras, o hay que hablar de leyes en función de su más alto grado de perfección o hablar de otra cosa. Entonces vino la respuesta de los historiadores que reaccionaron con sus viejos reflejos de siempre; en lugar de relevar el desafío de la reflexión crítica de Popper (como lo invita Perry Anderson con la de Fukuyama), ellos se defendieron justificando retóricamente la pertinencia de las leyes históricas. Unos hablaron de la fractura epistemológica entre el conocimiento de 
la naturaleza y del hombre, este último con una dimensión indeterminada ${ }^{7}$. Los demás, más cautelosos, hablaron de leyes, que en historia, serían algo como "vías de desarrollo". También hablaron de principios semejantes a leyes o de generalizaciones, o si no de cuasi - leyes o hipótesis (estas últimas serían más perfeccionadas que las generalizaciones, las cuales por su parte, serían el producto del sentido común). En consecuencia, la ley tal como es entendida en las ciencias puras, constituiría la ambición suprema. Una historia que se quiere verdaderamente científica debe aspirar fuertemente a serlo, razón por la cual está autorizada a referirse a esta noción, aunque todavía no pueda lograr el nivel generado por el conocimiento nomotético. Porque se logrará algún día ${ }^{8}$. Estos son los historiadores que generalmente, suelen hablar de la historia como de una "ciencia en construcción". ¿No es en este tipo de afirmación que se encuentra, justamente, toda la "miseria" del historicismo?

\section{XXIV}

¿Qué es lo que queda, entonces, para continuar la reflexión sobre la historia científica? ¿La búsqueda de la objetividad? Esta es ante todo un problema ético. ¿El rigor? Para esto no hay ninguna necesidad de ciencia: la honestidad, el amor al trabajo bien hecho y el sentido común son ampliamente suficientes. Y que nos guste o no, las interpretaciones históricas basadas en el common sense tuvieron más efec-:os durables y, sobre todo, causaron menos daños que las que se querían científicas. ¿El método entonces? El arte y la música lo reivindican también y no se consideran necesariamente como "ciencias". Quedaría el principio primero: la búsqueda de la Verdad. Es lo último que según algunos quedaría para legitimar la pretensión de la historia de definirse como ciencia, y ello a pesar de sus numerosas imprecisiones conceptuales, a pesar que no sería todavía una ciencia en el pleno sentido de la palabra $^{9}$. Una pregunta surge desde ahora: ¿con todo lo que se ve en nuestros días, la búsqueda de la verdad no ha vuelto a ser un asunto demasiado importante para ser puesta en las solas manos de la ciencia?

\footnotetext{
${ }^{7}$ Lo que Popper reúne bajo la categoría de doctrinas antinaturalistas. Véase Karl Popper, La Miseria del Historicismo (Madrid: Taurus, 1985).

${ }^{8}$ Jerzy Topolski, Metodología de la Historia (Madrid: Cátedra, 1985).

${ }^{9}$ Jaques Le Goff, Pensar la Historia: Modernidad, Presente, Progreso (Barcelona: Paidós, 1991), 31-35.
} 


\section{XXV}

Barthes escribió a propósito de la objetividad y del sentido de lo real en la literatura algunas frases que los historiadores deberíamos interesarnos en seguir ${ }^{10}$. Respecto a la objetividad, cuando nos esforzamos en mirar las cosas desde el "exterior", a pesar de que logramos desarrollar todo tipo de metodologías que "domestican nuestra subjetividad" (según la expresión de Ricoeur), llegamos siempre a la formulación de interpretaciones que varían de un analista al otro. En lo referente a la realidad, aunque todo escrito literario puede contener un sentido literal (el sentido querido por el autor), se comprueba inmediatamente, por la naturaleza simbólica del lenguaje, que el escrito contiene inevitablemente otros sentidos. La cuestión, desde luego, consiste en demostrar que estos significados no contradicen infraganti este sentido literal. Entonces, el problema del sentido primero, del sentido "real", constituye un problema de filología o de diccionario, mas no de metodología o de cualquier tipo de fundamento metafísico.

\section{XXVI}

Sin embargo hay un elemento que, a juicio de algunos historiadores, justifica por sí solo toda la pretensión cientificista: la dinámica del cambio. Aquí está por lo menos un fenómeno cuya comprensión nomotética fundamenta por sí solo toda la ambición de una historia científica. Pero el cambio... En fin: ¿Qué es el cambio? ¿Qué es una ley histórica del cambio? ¿La comprensión del progreso como fenómeno histórico? ¿Qué es lo que certifica que todo cambio corresponde a un progreso? Puede serlo sin ninguna duda. Precisando aún más la pregunta: ¿qué es lo que dice que el progreso conduce hacia algo inevitablemente mejor (o peor, pero que terminará por llevarnos hacia algo mejor, como en toda filosofía redentora de la historia, de San Agustín a Marx)? Nada. La única ley a la cual obedece el cambio es la de cambiar. Nada más. Pero el día que se asimile esto, no estaremos ante una ley demostrada. Sino ante una tautología.

\footnotetext{
${ }^{10}$ Roland Barthes, Crítica y Verdad (México: Siglo XXI, 1991), 17-20.
} 


\section{XXVI}

La filosofía, como el derecho, no son conocimientos que hacen parte de las ciencias. ¿Ellos se sienten disminuidos en cuanto a su legitimidad cognoscitiva? ¡ $\mathrm{Al}$ contrario! ¡No se sienten acomplejados de ninguna manera! Numerosas son las artes que contienen elementos relacionados con principios científicos. Del reerso de la mano, los más desdeñosos de los artistas descartaron, descartan y descartaran todos los intentos absurdos de encerrar su quehacer en la "científicidad". So1o los que no tienen talento, respondían, tienen semejantes ideas. Eso es lo que se afirmaría y nada más. Me pregunto pues: ¿por qué nos esforzamos tanto desde hace casi dos siglos en ser lo que, definitivamente, no estamos destinados ser? O quizás sería más apropiado decir: ¿qué es lo que incomoda tanto en la demostra;:ón de que la historia no sea una ciencia, a varias generaciones de historiadores? ¿Buscan estas críticas desacreditarla, realmente? ¿O será más bien que buscan restituir su dignidad, nuestra dignidad? ¿La explicación de estos ataques cada vez más encarnizados a la crítica, se encontraría, en la terquedad de los historiadores ?

\section{La pregunta merece reflexión.}

\section{XXVII}

¿Ques lo que el postmodernismo ha aportado hasta ahora a la crítica de la modernidad en el conocimiento histórico? ¿Qué es lo que ha aportado que no ha sido criticado desde la misma modernidad? Que uno juzga por sí mismo. La problemática de los fenómenos sociales como "acto lingüístico" fue abordada primero por Rousseau ${ }^{11}$. El relato histórico empírico como representación ficticia de una realidad espacio-temporal fue una idea kantiana ${ }^{12}$. La implicación del sujeto en el análisis de los procesos históricos hacía parte de los planteamientos básicos de una visión idealista de la historia tal como la defendía Fichte ${ }^{13}$. Y se podría

\footnotetext{
${ }^{11}$ Jean-Jacques Rousseau, "Discurso sobre el Origen y los Fundamentos de la Desigualdad entre los Hombres," pt. 2 en Del Contrato Social (Madrid: Alianza, 1998), 276-316.

${ }^{12}$ Emmanuel Kant, "Si el Género Humano se Halla en Progreso Constante hacia Mejor," en Filosofía de la Historia (Bogotá: Fondo de Cultura Económica, 1994), 95-122.

${ }^{13}$ Johann Gottlieb Fichte, Los Caracteres de la Edad Contemporánea (Madrid: Revista de Occidente, 1954), 229-43.
} 
continuar citando ejemplos similares hasta el infinito. Entonces, señores posmodernistas, no me impresionan sus supuestas críticas "cáusticas" sobre la metahistoria o la historia ficción.

\section{XXIX}

Para poder integrar lo científico en el conocimiento histórico, el historiador buscó eliminar la pasión - empezando por la suya — en el estudio del pasado. Pero todo lo que ha logrado hacer es generar una nueva pasión negativa: el odio de la historia hacia la narrativa. ¡Sin embargo, mirad si no hay pasión en la muy científica historia marxista, o narratividad en la "larga duración" de los historiadores de la Escuela de los Anales!

\section{XXX}

Así, la historia científica habría relegado la historia narrativa a los calabozos de la fantasía... ¡De veras! Miremos este problema detenidamente... Comenzamos por la acción de relegar, la cual frecuentemente disimula un desquite de resentimiento del historiador. Así se desvela toda su mezquindad frente a la narratividad: si la combatió ferozmente, implacablemente, sistemáticamente, era con la intención de abrir las puertas a la vulgaridad y la mediocridad propias a todo igualitarismo por abajo. Así, se remplazó el entusiasmo frente a lo maravilloso, inherente a todo hecho del pasado, a toda la gama de emociones producidas por la lectura de los documentos, a todo el placer procurado por la comunicación de nuestros hallazgos sobre el pasado, todo esto fue reemplazado por la aplicación mecánica de una serie de técnicas. Lo que otrora demandaba tacto, perspicacia, refinamiento y creatividad, ha sido reemplazado por el esfuerzo (como el del burro), por el virtuosismo (ejecución perfecta sin emoción), y el quehacer (como taylorismo intelectual). Al artista se le sustituyó por el obrero. Los Ranke y los Guizot se impusieron como modelo, contra los Michelet y los Macaulay. Y se afirma que de esta manera, ganó el conocimiento histórico en credibilidad. ¿De veras?

\section{XXXI}

El cientificismo supondría el ardor en el trabajo como garante de objetividad. 


\section{XXXII}

Luego, no se puede confundir más: el animal totémico del historiador - y eso es más cierto todavía para el "teórico" — no debe ser la mula sino el toro.

\section{XXXIII}

Monod señaló que su vocación de historiador vino a través de la lectura de Michelet ${ }^{14}$. i Qué grandes verdades salen (a veces) de la boca de la inocencia positivista!

\section{XXXIV}

El pensamiento histórico científico, entre otras cosas, por reducir el conocimiento del pasado a una cuestión de método, tuvo el mérito, altruista eso sí, de permitir el ingreso de los laboriosos a la carrera académica. Sin embargo, en términos de apertura de las cátedras universitarias a la mediocridad cognoscitiva, la palma va sin ninguna duda para los historiadores que se reclaman posmodernos, quienes atacando a la casta de los "técnicos" de la teoría y del método, ampliaron el panorama aún más, afirmando que el historiador está autorizado a decir del pasado lo que le venga

en gana.

\section{XXXV}

He entendido al hombre común y corriente, cuando dice hasta la saciedad que el estudio de la historia no sirve para nada porque no afecta o mejora significativamente su vida cotidiana. He entendido también a algunos historiadores cuando afirman: "tal como está diseñado este programa académico de historia no sirve para nada". Porque si para el primero, el individuo que posee un conocimiento histórico no puede sólo a partir de este bagaje cognoscitivo, reparar su televisor o su automóvil, objetos de una peculiar trascendencia para él, para los segundos, en cambio, la adquisición de un saber académico, significa que el estudiante egresado no sirve para ser su asistente de investigación cuya tarea

\footnotetext{
${ }^{14}$ Citado en: George Gooch, History and Historians in the Nineteenth Century (Boston: Beacon, 1959), 177.
} 


\section{FRONTERAS}

consiste en localizar (y fotocopiar) los fondos de archivos y copiar las referencias bibliográficas, tampoco sirve como técnico de la historia, por ejemplo archivista, maestro preuniversitario o museologo. No quiero decir que estas profesiones no son "nobles" en sí - iln'y apas de sot métier! — pero, al aislarlas de su contexto académico e intelectual, se reduce a sus ejecutantes a simples "operarios de máquinas" para los happyfew detentores del capital cognoscitivo. En conclusión, estos dos puntos de vista frente al conocimiento histórico, que parecen oponerse al principio, convergen como las dos caras de una misma moneda, la de la cientificidad, en una de sus mayores características: el aprendizaje de un saber con fin utilitario.

\section{XXXVI}

¡Como si el conocimiento histórico no estuviera ya suficientemente desacreditado así! Ha aparecido el más reciente avatar de la historia científica: el tecnócrata. ¿El último suspiro del moribundo? ¿ $\mathrm{O}$ la forma extrema de nihilismo?

\section{XXXVII}

La historia, por su indeterminismo continuamente creativo, es un conocimiento destinado par excelence a los que aspiran a la libertad, como Kant lo dio a entender $^{15}$. Pero desde hace casi doscientos años, ha sido asaltada por los adeptos de una moral de esclavo.

\section{XXXVIII}

Todo pensamiento científico es un reduccionismo. Así debe ser considerada también toda idea de "ciencia humana". Comte fue muy claro al respecto. Pensar científicamente la sociedad significa reducirla a sus dimensiones reales; el descubrimiento de sus leyes efectivas implica el abandono explícito y definitivo de toda búsqueda de trascendentalismo ${ }^{16}$. Pero fuera de fines puramente médicos (iy todavía!), este reduccionismo como principio último de la comprensión "objetiva" del hombre ¿no constituye en sí algo profundamente grosero? ¿Más que mejorar la

\footnotetext{
${ }^{15}$ Kant, "Idea de una Historia Universal en Sentido Cosmopolita," en Filosofía de la Historia, 39-65.

${ }^{16}$ Auguste Comte, Curso de Filosofía Positiva (lecciones 1 y 2): Discurso sobre el Espíritu Positivo (Barcelona: Orbis, 1980), 25-31.
} 
condición humana, este reduccionismo, al finalizar el siglo XX no ha dado acaso argumentos y recursos a todos los imbuidos de poder para cometer una multitud sin fin de abusos?

\section{XXXIX}

El lado definitivamente trágico de todo conocimiento teórico es llegar a una profundidad tal en la comprensión del problema, que termina uno lanzándose al vacío con el asunto del cual quería "desembarazarse". Pero ¿dónde están estos insensatos que tuvieron suficiente sabiduría para hacerlo? ¿Dónde están estos locos que osaron lanzarse al precipicio sin nunca preguntarse si abajo había algo para recogerlos? ¡Que nadie se atreva a decirme que logré ser uno de aquellos! ¡Estoy todavía por preguntarme si algún día llegaré a tener suficiente coraje para ser capaz por lo menos de bailar al borde del precipicio!

XL

La historia científica (y no la historia como tal). ¿No será la cosa más nociva que haya producido la química del intelecto humano?

\section{XLI}

En el transcurso de dos siglos de espíritu científico - y en este siglo en particular — la pretensión es enorgullecerse de haber logrado, de la misma manera que enseña el evangelio, a separar le bon grain de Vivraie. Lo que corresponde en otras palabras, a sustraer el conocimiento histórico de las manos de los aficionados carentes de formación profesional ${ }^{17}$. ¿Pero por haber dado también pruebas de amateurisme, además de haber cultivado, conscientemente o no, el resentimiento, por haber ventilado sus ilusiones, sus mitos y, aún peor, por haber reducido todo el conocimiento sobre el pasado a cuestiones metodológicas y técnicas. Finalmente, por haber abierto el campo a los laboriosos y a los mediocres, la historia científica, no habría acaso, separado Vivraie du bon grainl

\footnotetext{
${ }^{17}$ Véase para el caso de América Latina el artículo de Heraclio Bonilla, "Diseño de una Licenciatura en Historia con Énfasis en la Historia de América Latina: Una Propuesta para su Discusión," Historia y Pensamiento, no. 2 (Junio - Diciembre 1997): 8.
} 


\section{XLII}

¿Hay que sorprenderse de todo eso? De lo que se trata aquí, es de comprender uno de los más grandes engaños cognoscitivos cuyo resultado fue estancar el conocimiento histórico casi durante dos siglos. La crítica del cientificismo en la historia está relacionada con su legitimidad cognoscitiva. Sin embargo, esa crítica no puede limitarse a la constatación del problema. Eso no es suficiente. No puede ser suficiente. No se trata sólo de retirar la máscara del cientificismo puesta en la cara del historiador, máscara que él mismo se ha colocado, aún cuando no lo ha fabricado. Es también, y sobre todo, analizar la función simbólica de esta máscara y la necesidad que ha tenido el historiador de lucirla. Desde hace demasiado tiempo los análisis alrededor de esta temática se limitaron a la actitud cómoda de dar cuenta del problema en lugar de diagnosticarlo con la intención de buscar una curación posible. Si es que ella existe. De una manera u otra, no podrá ser otra cosa que la superación del cientificismo. Establecer los contextos en lugar de refutar. Hacer "tabula rasa" en lugar de hacer una "demostración irrefutable". ¿Será que perdimos a los provocadores de antaño ${ }^{18}$

\footnotetext{
${ }^{18}$ Friedrich Nietzsche, Aforismo 95 en Aurora.
} 